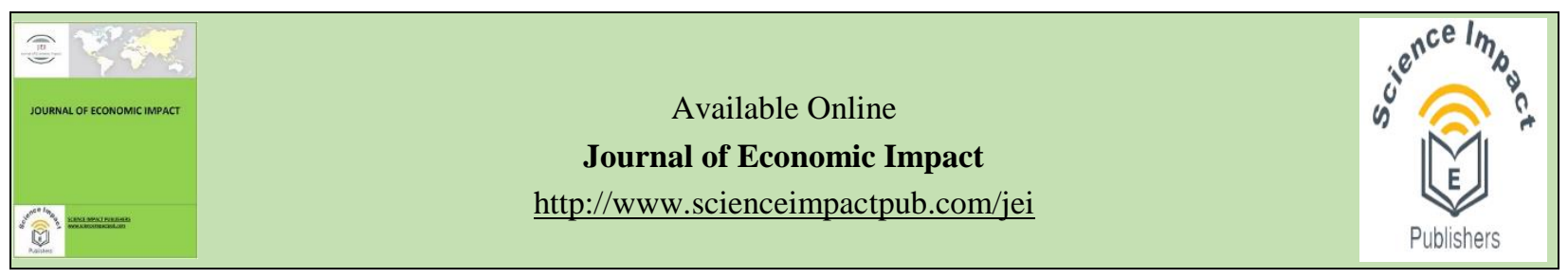

\title{
DECOMPOSITION ANALYSIS OF WHEAT GROWTH AND ITS POLICY IMPLICATIONS IN PAKISTAN
}

\author{
Muhammad Faisal Ali ${ }^{\text {a, }}$, Sobia Rose ${ }^{\text {b }}$, Sarfraz Hassan ${ }^{\text {a }}$, Muhammad Ashfaq ${ }^{\text {a }}$ \\ a Institute of Agricultural and Resource Economics, University of Agriculture, Faisalabad \\ b Punjab Economic Research Institute, Planning and Development Department, Govt. of Punjab, Pakistan
}

\section{HIGHLIGHTS}

- The study decomposed wheat growth into the area, yield and their joint effect from 1947 to 2016 both overall and decade wise to study any structural breakdown overtime.

- This study concluded growth rate analysis as an important tool for policymakers to comprehend the impact of applied policies.

- This study found the highest growth rate of wheat in the period of the green revolution and after that yield declined and became lower than our neighboring countries in the region like China and India.

- The results of the decomposition analysis exhibit that yield of the wheat has increased over time while area share has decreased which is mainly because of rapid urbanization and mounting population pressure.

- Water scarcity, changing climatic conditions and low input productivity have caused reduced yield potential of wheat in the country.

\section{ABSTRACT}

Wheat is an incredibly political crop because of its inelastic demand in Pakistan. Wheat accounts for almost 50 percent calorie intake in the country with a relatively greater share in total calorie intake in rural areas of the country. Despite the sensitivity of this crop, it is always challenged by various factors like climate change along with other economic and political influences make it difficult to meet the nutrient requirement of the rapidly growing population. For a better-informed policy framework, it is necessary to study the previous patterns of growth of the wheat crop and its contributing factors to formulate more vigorous growth targets of the wheat crop in the future. For this purpose, we decomposed wheat growth into the area, yield and their joint effect from 1947 to 2016 both overall and decade wise to study any structural breakdown overtime. The results of the decomposition analysis reveal that the area contribution of wheat remained 35 percent while yield contribution was 61 percent. The same is the case in decade wise analysis which reveals that in future yield can be increased by adopting favourable policies to harness the yield potential of wheat in the country.

Keywords: Wheat growth; decomposition analysis; yield; policy; Pakistan.

Received: Feb 16, 2020; Accepted: March 30, 2020; Published: April 04, 2020.

* Correspondence: Institute of Agricultural and Resource Economics, University of Agriculture, Faisalabad

Email: faisalaliuaf@gmail.com

\section{Introduction}

Pakistan is an agriculture-based economy with a larger share of the sector in all the growth indicators (Asif, 2013). The share of the agriculture sector in annual GDP remained 18.5 percent along with a 38.5 percent share in the labor force of the country (GOP, 2019). This makes its role very critical for the overall development of the country (Ahmad et al., 2002). Among all crops, wheat has always remained at the utmost policy agenda for policymakers as it is the major staple food in the whole country therefore cultivated on the largest acreages.
Wheat crop is incredibly political in Pakistan because of its sensitivity among consumers. The production of the crop increased by 0.5 percent as compares to the fiscal year 2018 while its contribution in value-added and GDP is 8.9 and 1.6 percent respectively (GOP, 2019). Further, it provides almost 60 percent of daily diet to a common man with $125 \mathrm{~kg}$ per capita consumption, therefore, it helps government efforts in achieving food security in the country (PARC, 2016). Moreover, wheat accounts for almost 50 percent calorie intake in Pakistan (Ahmed 
and Jansen, 2010) however, this share is greater among rural households where dietary patterns are mainly featured with the bread of wheat flour (Hussain et al., 2014). Hence, agriculture is imperative and wheat is vital.

Despite its high importance, the agriculture sector is challenged by various factors out of which climate induced disasters are major ones that threatened the food production systems and consequently the livelihoods and food security of billions of people are at stake (Adger et al., 2003). Pakistan is also one of those countries whose population is mounting rapidly therefore more nutrients requirement is a precondition for an increasing population that can only be reached by more production of wheat. Although, Pakistan remained almost self-sufficient in wheat production during last three decades (Khan, 2000; Hussain and Routray, 2012) but the government still has to import wheat from different countries to bear the burden of a growing population and to cope with some natural shocks like floods and earthquake (Ahmad et al., 2002; Hussain and Routray, 2012).

Wheat production along with pricing policy depends on many other factors like machinery, agricultural labor and fertilizer utilization. Due to the inadequate supply of inputs such as improved seed, fertilizers, and pesticides, only 32 percent of potential had been harvested in wheat yield in Pakistan (Muhammad, 2000). Reducing the gap between actual and potential yield and enhanced accessibility to the marginalized groups at affordable prices is required to ensure food security (Sulehri and Ramay 2009; Cumming et al., 2006). Subsidizing and in time availability of the inputs can help in improving the situation (Ali et al., 2011). But, the generation after generation of land division has given rise to many small farmers who cannot afford modern equipment that also led to more reduction in the production of wheat.

Although Pakistan is the 8th largest wheat producer in the world with 25,600 thousand metric tons production but with respect to the growth rate (1.99 percent) Pakistan stands at 36th in the world which is even lower than its neighbouring countries like India (2.32 percent) (Indexmundi, 2019). This lower growth rate is also highlighting growth potential for wheat in Pakistan that requires a thorough understanding of past trends in wheat growth and its contributing factors. The production of wheat has always been fluctuating and normally remained below the consumption requirement in Pakistan (Abbas et al., 2007). Semi-dwarf wheat has a genetic yield potential of 6-8 tons per hectare but wheat productivity is still around 2.7 tons per hectare which makes it imperative to enhance the production potential of wheat in the country (Yaqub, 2011).
Investigating major contributing factors of growth requires its decomposition i.e. area and yield and for this purpose, component analysis or decomposition analysis will be used which will help policymakers in making better output projections keeping in view the share of the contributing factors (Jamal and Zaman, 1992). Further, analysis of past trends in wheat production and rate of growth provides insight into whether wheat production remains expansionary of it was based on intensification strategies.

Very little literature is available on a decomposition of the growth rate of any crop. Mahir and Abdelaziz (2010) studied the growth rate for the area, productivity and production and component analysis of the main crops in Gezira for only two time periods. Shadmehri (2008) studied the growth rate trends in the area, production and yield in Iran for pre and the post-revolutionary period from 1970 to 2000. Rehman et al. (2011) did the same analysis in Pakistan on wheat from 1972-2009. However, this study missed the data from 1947-71. This study focuses on historical trends of wheat growth and its contributing factors with a more precise decade wise analysis and also presents an overall picture. Hence, the objective of this study was to examine growth trends in the wheat area, production, and yield, secondly, to investigate sources of output growth of wheat in Pakistan.

\section{Methodology}

This study focused on growth rate analysis of wheat production and decomposition of growth factors contributing to wheat production from 1947 to 2016 in Pakistan. For this purpose, time-series data on wheat production, area cultivated and yield were collected from different issues of economic survey of Pakistan. For estimating growth rates for the wheat area under cultivation, wheat production and yield, a method of compound growth rate was applied like Shadmehri (2008). The compound growth rate was calculated by using a semi-log trend equation.

$$
\operatorname{Ln} Y=\alpha+\beta \mathrm{t}
$$

Eq. 1

Where,

"Y" shows time series data of wheat area, production and yield.

" $\mathrm{t}$ " is the trend term

" $\alpha$ " is constant coefficient

And " $\beta$ " is the measurement of slope coefficient that represents the relative change in $\mathrm{Y}$ for a given absolute change in the value of explanatory variable " $t$ ". For growth rate of Y for an absolute change in the values of explanatory variable, relative change in $Y$ was multiplied by 100 . The component analysis model 
was used to estimate the relative contribution of area, yield, and their interaction effect in total output, This procedure had been used by Bastine and Palanisami (1994); Bhatnagar and Nandal (1994); Mundinamani et al., (1995); Gupta and Saraswat (1997); Singh and Ranjan (1998); Siju and Kombairaju (2001); Kakali and Basu (2006); Shadmehri (2008); Rehman et al., (2011). Total change in production is the function of area, yield, and their interaction so all these effects are decomposed as;

$$
\Delta \mathrm{P}=\Delta \mathrm{A} * \mathrm{Y}+\Delta \mathrm{Y} * \mathrm{~A}+\Delta \mathrm{A} * \Delta \mathrm{Y} \quad \text { Eq. } 2
$$

$\Delta \mathrm{P}=$ Change in production

$\Delta \mathrm{A} * \mathrm{Y}=$ Area effect

$\Delta \mathrm{Y}^{*} \mathrm{~A}=$ Yield effect

$\Delta \mathrm{A}^{*} \Delta \mathrm{Y}=$ Interaction effect

\section{Results and Discussion}

The study aims at decomposition of growth into its components to analyse which factor had affected most of the growth of wheat production. Area, yield and their interaction effects were taken into account to decompose the growth of total output to find factor contributed most in wheat production from 1947 to 2016. A summarized depiction of a trend in area and production of wheat growth from 1947 to 2017 is presented in appendix 1. For a detailed understanding of growth trends and decomposition analysis, this study contributed a detailed decade wise analysis that is missed in the existing literature. For this purpose, the entire study period was further divided into seven decades. Results for the overall study period and all decades are discussed in this section.

\section{Compound Growth Rate and Wheat in Pakistan}

The growth rate for an entire period of study was also estimated to comprehend the overall growth pattern of area, production, and yield. Findings in Table 1 indicate that the overall growth rate of the area was 1.3 percent while the annual average growth of production and yield was 3.6 and 2.3 percent respectively. The growth rate of yield for the whole study period was found quite lower ( 2.3 percent) than in many developing countries.

Table 1: Results of Compound Growth Rate (CGR) from 1947-2017

\begin{tabular}{cc}
\hline Factors & CGR \\
\hline Area & $1.3 \%$ \\
Production & $3.5 \%$ \\
Yield & $2.2 \%$ \\
\hline
\end{tabular}

The growth rate for the area showed a varying trend in different decades, it increased in the first two decades then it depicts the decreasing trend in the third decade after this suddenly it gets increased again in the fourth decade and after this, it showed a decreasing trend. Production and yield showed an increasing pattern up to the third decade after this both depicted decreasing trend.

Figure 1 presents compound growth rate for area 1.1 percent from 1947 to 1957 whereas production and yield depicted the negative growth which turned out positive from -1.3 to 1.7 and -2.4 to 0.3 for production and yield respectively in the second decade (19581967) when irrigation facilities were enhanced by the Government of Pakistan (Zaidi, 2005). The impact of increased water facilities was readily observed in the form of increased production through yield. It is also obvious from Figure 1 that the growth rate for the area also increased from 1.1 to 1.5 percent during the second decade due to agriculture friendly policies at that time and this era also regarded as the green revolution. Further growth potential was extracted in the third decade. The third decade come up with the introduction of high yielding varieties, use of fertilizer and technology so growth rates for production and yields jump to 3.7 and 3.5 percent respectively which was observed as the highest growth rate of yield and production in the history of Pakistan whereas growth rate for the area was minimum for this period $(0.2$ percent). This makes it clear that more production of wheat was made possible with the existing area in the third decade.

Area growth was minimum because new varieties were providing already higher yield hence lesser considerations were given to enhance the area under production. It is interesting to note that yield showed a decreasing trend in the fourth decade and reduced to 1.8 percent from 3.5 percent while the growth rate of production and area was 3.6 and 1.8 percent for this period. Outcomes for a succeeding period (1988-97) revealed that area, production, and yield were growing with a growth rate of $1.1,2.6$ and 1.7 percent respectively. Improved cultural practices and use of high yielding varieties along with the conversion of 
rain-fed land to irrigated land provide the basis for an almost same increasing trend in the area in next two decades but yield revealed a decreasing trend in last decade (2008-16) because higher support prices lead farmers to dedicate more area under wheat cultivation.

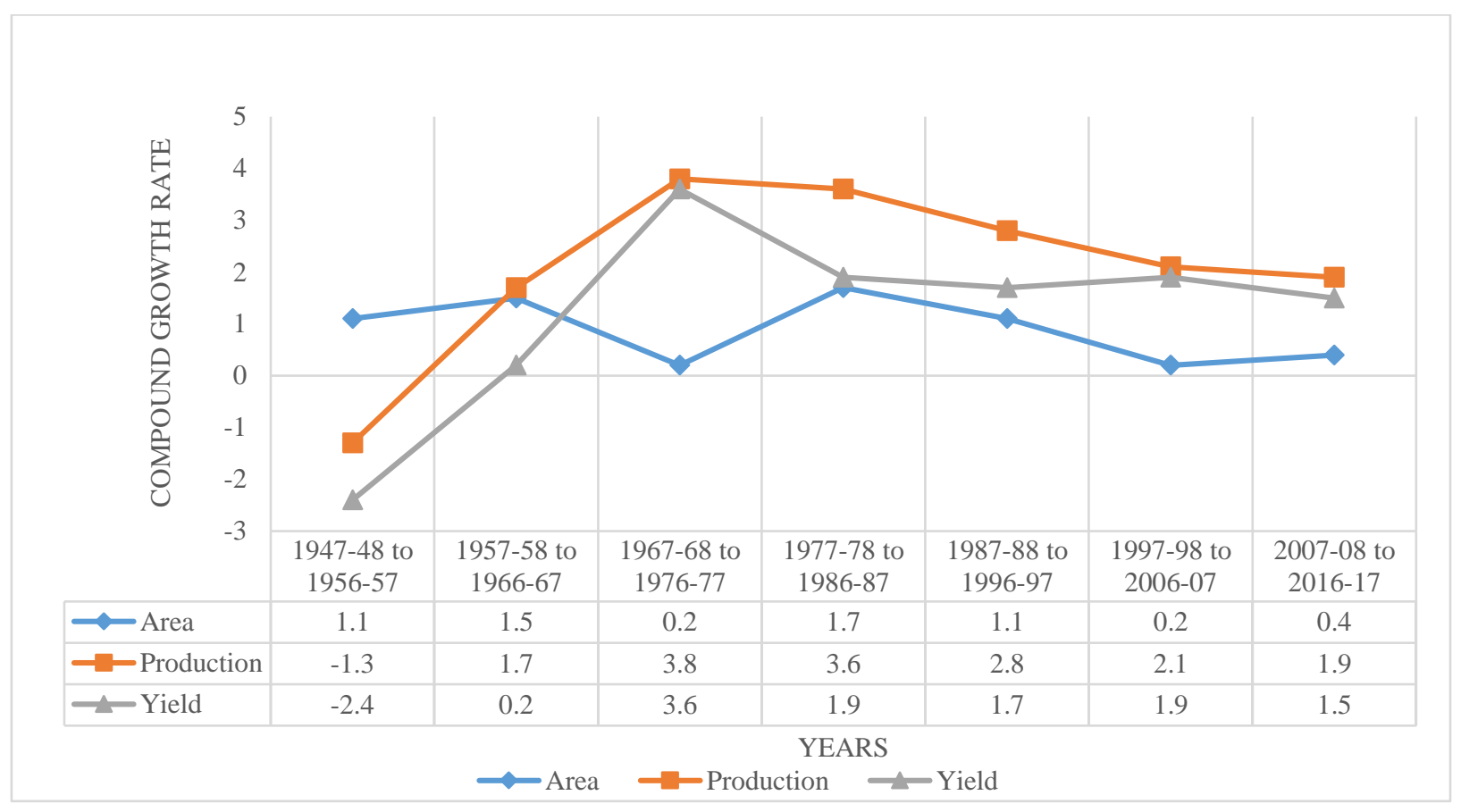

Figure 1: Decade Wise Compound Growth Rate of Wheat Area, Production and Yield

\section{Decomposition Analysis of Wheat Growth}

Growth analysis simply portrays a general pattern of growth and direction of changes. But it does not describe anything about the contribution of different growth factors i.e. area and yield, therefore, sources of output growth for the wheat crop were estimated. For this purpose, wheat production was divided into area effect, yield effect and their interaction effect. The results of the decomposition analysis are presented in Table 2.

Table 2: Decomposition Analysis of Wheat Growth

\begin{tabular}{|c|c|c|c|c|c|c|c|c|}
\hline Decomposition & $\begin{array}{c}1947-48 \\
\text { to } 2016- \\
17\end{array}$ & $\begin{array}{c}1947-48 \\
\text { to } 1956- \\
57\end{array}$ & $\begin{array}{c}1957-58 \\
\text { to1966- } \\
67\end{array}$ & $\begin{array}{c}1967-68 \\
\text { to } 1976- \\
77\end{array}$ & $\begin{array}{c}1977-78 \\
\text { to } 1986- \\
87\end{array}$ & $\begin{array}{c}\text { 1987-88 } \\
\text { to1996- } \\
97\end{array}$ & $\begin{array}{c}1997-98 \\
\text { to } 2006- \\
07\end{array}$ & $\begin{array}{c}2007-08 \\
\text { to } 2016- \\
17\end{array}$ \\
\hline Area & 30.11 & 181.92 & 74.55 & 22.24 & 72.63 & 18.45 & 15.36 & 28.73 \\
\hline Yield & 66.96 & -151.17 & 19.79 & 73.84 & 26.48 & 82.08 & 81.23 & 70.27 \\
\hline Interaction & 2.93 & 69.24 & 5.66 & 3.92 & 0.89 & -0.53 & 3.42 & 0.99 \\
\hline
\end{tabular}

The decomposition analysis of wheat exhibited yield as a major source of output growth for the entire period of study. Results indicated 61.16 percent change in wheat production through yield whereas the area effect explained 35.38 percent change in Pakistan while their joint interaction effect was found 3.45 percent.

For more precise fallouts, whole data of wheat production was divided into seven parts/decades and then decomposition analysis was applied to all 
decades separately. Results for the first period revealed that area effect (182.16 percent) was a major contributor to wheat production at the beginning of the history of Pakistan. However, the yield effect for this period was found negative (-151.51 percent) due to a greater contribution of an area in wheat production while the interaction effect was 69.35 percent. Although negative yield effect turned out positive in the second decade (1958-1967) due to provision of more irrigation facilities i.e. 24000 electric tube wells etc. to farmers by the government (Zaidi, 2005) but the area was found again as a major source of change in production with 75.56 percent area effect while yield and interaction effects for this period were 19.33 percent and 5.11 percent respectively.

The third decade (1968-77) was renowned as a period of a green revolution in Pakistan which comes up with high yielding varieties, fertilizer application and employment of technology in agriculture. Hence, noticeable impacts were also observed in the agriculture sector generally and for wheat crop especially. Therefore, outcomes for this period exposed yield as a major source of output growth in contrary to previous decades. The yield effect for this period was found 77.28 percent while the area effect was 21.03 percent along with a 1.69 percent interaction effect.

An interesting finding was observed in very next period to the green revolution, yield effect reduced due to increased cropping intensity, which causes late plantation of wheat that ultimately reduced production, increase disease attack coupled with weeds problems, lesser efficiency of fertilizer use and use of poor quality water of tube wells were the major reasons behind the reduced yield effect in this period (Byerlee and Siddiq, 1990). Area, yield and interaction effects for this period were 58.10 percent, 42.56 percent, and -0.66 percent respectively.

It is obvious from the findings that yield remained an important factor in wheat production in the next two decades due to the conversion of Rain-fed land to irrigated land, increased water supply, improved cultural practices and better fertilizer use along with the high yielding varieties brought yield effect higher.

Although yield's contribution to wheat growth was significant but lower and uneven as its effects again reduced in the last decade. It may happen because of governmental wheat support policies. A continuous increase in support price for wheat, PKR 425/40kg (GOP, 2007) to PKR 1300/40kg (GOP, 2016), was observed in the recent decade. This large increase created more benefits for farmers that are readily observed in an area under wheat cultivation. Consequently, the area effect was observed as the largest contributor to wheat production in the recent decade (2008-16). Hence, productivity remains a greater concern which needs much emphasized planning in order to harvest existing potential (Murgai et al., 2001).

\section{Conclusions}

This study concluded growth rate analysis as an important tool for policymakers to comprehend the impact of applied policies because it provides a direction of change, either it is in the desired way or not. This study found the highest growth rate of wheat in the period of the green revolution and after that yield declined and became lower than our neighboring countries in the region like China and India which reveal that there is room for improvement. Policies must favor and stimulate wheat productivity in the country. The results of the decomposition analysis exhibit that yield of the wheat has increased over time while area share has decreased which is mainly because of rapid urbanization and mounting population pressure. Water scarcity, changing climatic conditions and low input productivity have caused reduced yield potential of wheat in the country. Hence, there is an urgent need for high yielding varieties suited to agro-climatic conditions to fulfil the growing needs of increasing populations. Programs should be designed to support a high yield of wheat. Strengthening agricultural research and extension, improvements in the irrigation system, Support price together with the technology, adequate water availability, formulation of pricing and marketing policies favorable to agricultural production, etc. are examples of such programs. By targeting small farmers in major wheat-growing districts will lead to higher growth performance that will ultimately reduce rural poverty.

\section{References}

Abbas, M., Sheikh, A. D., Shahbaz, M., Afzaal, A., 2007. Food security through wheat productivity in Pakistan. Sarhad Journal of Agriculture, 23(4), 1239.

Adger, W.N., Huq, S., Brown, K., Conway, D., Hulme, M., 2003. Adaptation to climate change in the developing world. Progress in development studies, 3(3), 179-195.

Ahmad, M., Chaudhry, G.M., Iqbal, M., Khan, D.A., 2002. Wheat Productivity, Efficiency, and Sustainability: A Stochastic Production Frontier Analysis [with Comments]. The Pakistan development review, 41(4), 643-663.

Ahmed, S., Jansen, H.G., 2010. Managing food price inflation in South Asia. World Bank Publications.

Ali, A., Rehman, F., Nasir, M., Ranjha, M.Z., 2011. Agricultural policy and wheat production: a case study of Pakistan. Sarhad Journal of Agriculture, 27(3), 201-211. 
Asif, M., 2013. Climatic change, irrigation water crisis and food security in Pakistan (Dissertation). Retrieved from http://urn.kb.se/resolve?urn=urn:nbn:se:uu:diva211663

Bastine, C.L., Palanisami, K.P., 1994. An analysis of growth trends in principal crops in Kerala. Agricultural Situation in India, 48(12), 885-891.

Bhatnagar, S., Nandal, D.S., 1994. Growth in wheat in Haryana. Agricultural Situation in India, 49(1), 75-78.

Byerlee, D., Siddiq, A., 1990. Sources of growth in wheat yields in Pakistan's Punjab, 1965-2000: Is there a sustainability issue?. CIMMYT Economics Working Paper 90/04, [Online] http://repository.cimmyt.org/xmlui/bitstrea $\mathrm{m} /$ handle/10883/1145/26436.pdf?sequence $=1$

Cumming, R., Rashid, S., Gulati, A., 2006. Grain price stabilization experiences in Asia: What have we learned? Food Policy, 31(4), 302-312.

GOP., 2007. Agricultural statistics of Pakistan. Ministry of Food, Agriculture and Livestock. Government of Pakistan, Islamabad.

GOP., 2016. Agricultural statistics of Pakistan. Ministry of Food, Agriculture and Livestock. Government of Pakistan, Islamabad.

GOP., 2019. Economic Survey of Pakistan. Finance Division Economic Advisor Wing, Government of Pakistan, Islamabad.

Gupta, B.S., Saraswat, P.K., 1997. Growth of rapeseed and mustard in Western Rajasthan. Agricultural Situation in India, 54, 261-264.

Hussain, A., Routray, J.K., 2012). Status and factors of food security in Pakistan. International Journal of Development Issues, 11(2), 164-185.

Hussain, A., Zulfiqar, F., Saboor, A., 2014. Changing food patterns across the seasons in rural Pakistan: Analysis of food variety, dietary diversity and calorie intake. Ecology of food and nutrition, 53(2), 119-141.

Indexmundi., 2019. [Online] http://www.indexmund i.com/agriculture/?commodity $=$ wheat $\&$ graph $=$ pro duction

Jamal, H., Zaman, A., 1992. Decomposition of growth trend in agriculture: Another approach. Indian Journal of Agricultural Economics, 47(4), 644.

Kakali, M., Basu, P., 2006. Measurement of growth trend: An econometric study of food grains production in west. Bangladesh J. Agric. Econ. 3(3), 44-55.

Khan, M.A., 2000. Food security in Pakistan. Asian Productivity Organization, Tokyo.
Mahir, M.E.A.E., Abdelaziz, H.H., 2010. Estimation of growth rates and analysis of its components in the Gezira scheme. Research Journal of Agriculture and Biological Sciences, 6(6), 885-890.

Muhammad, A., 2000. Seed Policy and Programmes in the Near East and North Africa: Improved seed production and technology transfer to farmers in the Nena Region. Food \& Agriculture Org, USA.

Mundinamani, M.S., Sastry, K.N.R., Venkatesh Murthy, T.N., 1995. Growth performance of oilseeds in Karnataka. Agricultural Situation in India, 52, 451-456.

Murgai, R., Ali, M., Byerlee, D., 2001. Productivity growth and sustainability in post-green revolution agriculture: The case of the Indian and Pakistan Punjab. The World Bank Research Observer, 16(2), 199-218.

PARC., 2016. https://www.google.com.pk/webh $\mathrm{p}$ ? sourceid $=$ chrome instant $\& \mathrm{rlz}=1 \mathrm{C} 1 \mathrm{CHZL}$ _enPK713PK713\&ion=1\&espv=2\&ie $=U T$

$\mathrm{F}-8 \# \mathrm{q}=$ wheat+in+pakistan (Last accessed, 7 Feb. 2017)

Rehman, F.U., Saeed, I., Salam, A., 2011. Estimating growth rates and decomposition analysis of agriculture production in Pakistan: pre and post sap analysis. Sarhad Journal of Agriculture, 27(1), 125-131.

Shadmehri, M.T.A., 2008. Estimating growth rates and decomposition analysis of agricultural production in Iran (1970-2000). Agriculture Economics, (1), 14-28.

Siju, T., Kombairaju, S., 2001. Rice production in Tamil Nadu: A trend and decomposition analysis. Agricultural situation in India, 58(4), 143-146.

Singh, R.K.P., Ranjan, K.P., 1998. Growth and instability in production of principal food grain crops: A case of backward economy. Bangladesh Journal of Agricultural Economics, 21(1-2), 1-20.

Sulehri, A.Q., Ramay, S.A., 2009. Food security where we are (Current Status) and where we want to go (Way Forward). Parliament of Pakistan, Strengthening Democracy through Parliamentary Development, UNDP, Islamabad.

Yaqub, M., 2011. National coordinated wheat programme, NARC, Islamabad. [Online] file:///F:/Work percent 20 on percent20Articles/Wheat...Area percent20production percent20and percent20yield.htm.

Zaidi, S.A., 2005. Issues in Pakistan's Economy, Oxford,University Press, Karachi. 


\section{Appendix}

Appendix 1: Trends in Wheat by Production and Area Cultivated (1947-2017)

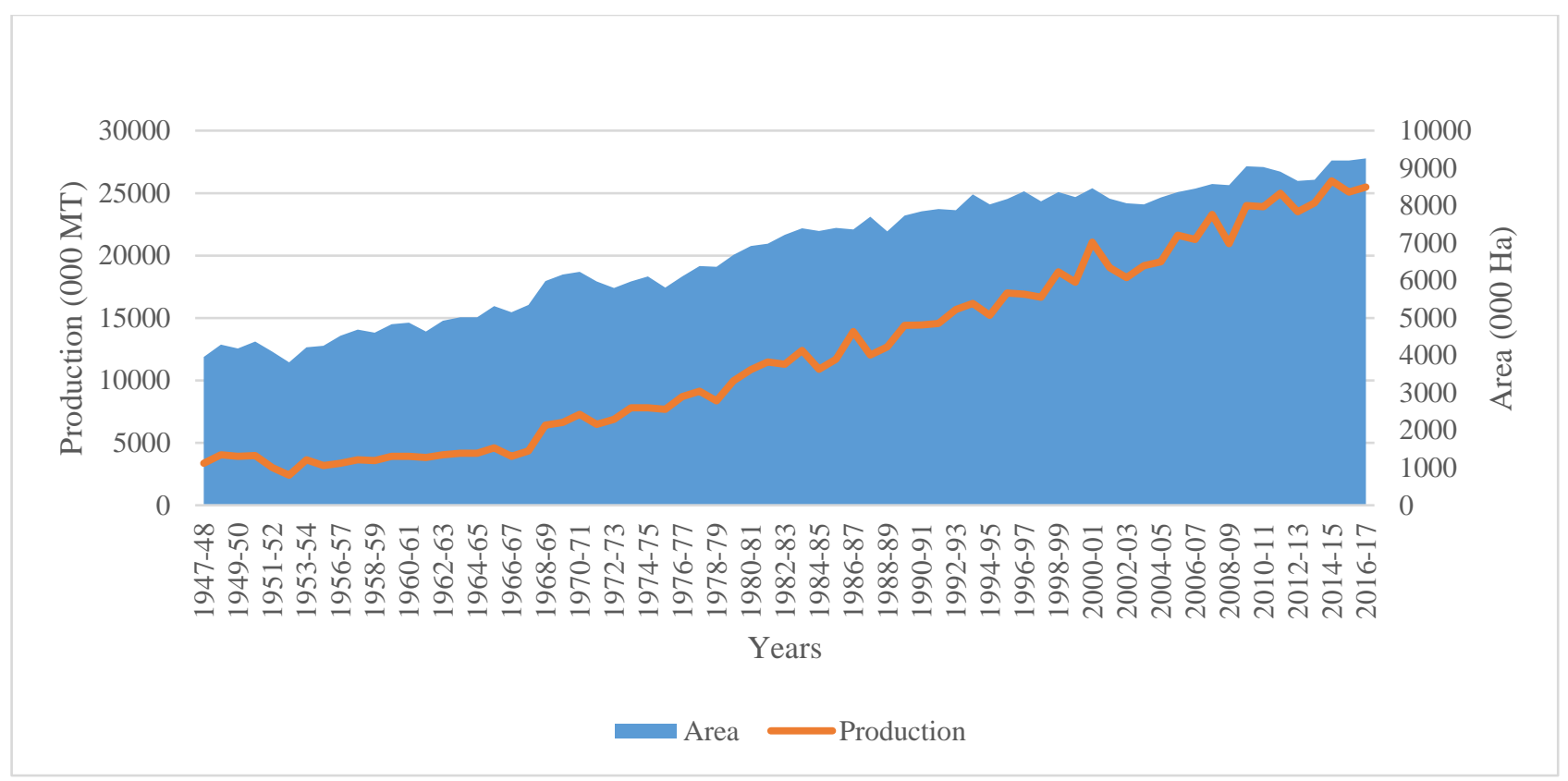

